\title{
A Critical Appraisal Of Covid-19 In India
}

\author{
Dr. Pradip Kumar Das \\ Jagannath Kishore College, Affiliation \\ Sidho-Kanho-Birsha University \\ Cooks' Compound, Purulia
}

\begin{abstract}
COVID-19 virus causes respiratory problems including pneumonia, cold, sneezing and coughing, and transmits human to human or human to animal via airborne droplets. World Health Organization advises to avoid public gatherings and close contact to infected persons and pet animals. India has made several precautionary measures to mitigate the disease at the initial stage. However, the density of population in India makes it difficult to control the disease, if government does not incorporate the visionary strategies. Since attacked several nations have been worried for their people lives, developing country like India with huge population should consider about the livelihood of the people belonging to below poverty line or BPL equally with other life. This paper will give insights to make effective strategy to culminate the world threat COVID-19 in India.
\end{abstract}

Keywords: COVID-19; India; Healthcare; Strategies; Community hospital.

\section{INTRODUCTION}

SARS-COV-2 virus promoting respiratory problems and ease of spreading through air make severe life threats. After outbreak from China, affected patients with COVID-19 in India are increasing and still it continues. Lesser mortality rate than other pandemic diseases is an overall good sign [1]. Although fatality ratio is statistically less, affected patients are increasing in the rate of multiplication. Indian government has taken few important strategies and policies to eradicate COVID-19 much early for the welfare of the people. Indian scenario on COVID-19 is decently better than the other affected countries due to early precautionary measures [2] undertaken by the government to restrain the spread. This paper will describe some insights to constrain COVID-19 for Indian life and livelihood.

\section{DISCUSSION}

Following international movements, Indian government has announced major strategies and policies to arrest COVID-19. Lock-down and isolation are important tools to prevent the new virus spread in practical scenario of India. Detection capacity (RT-PCR test) of infected patients in the epidemic zone is increasing. Many patients are undiagnosed. In this high time, India should address the situation with less mortality. This is much required to prepare medical set-up and proceed for future course of action. Some people are quarantined and few are left undetected due to mild symptoms or no symptoms, hiding travel history, etc. These indistinct connections are expected to spread the disease in community. 


\section{Features/Characteristics}

COVID-19 virus has been identified and sequenced genetically [3].The most likely route of transmission of COVID-19 is by contact and respiratory droplets over short distances (1.5 m.) and also through fomites contaminated by said aerosols. Airborne transmission cannot be completely ruled out. Prolonged contact is the highest risk. Symptomatic patients produce the majority of infections; however, asymptomatic patients and patients in the incubation period may also increase infections ${ }^{[4,5]}$. The most common symptoms are fever, cough, dyspnea and myalgia or fatigue, the most frequent being pneumonia and adult respiratory distress syndrome; $80 \%$ complicated cases are above 60 years. Few patients also report bilateral abnormalities Till, corona virus is not confirmed in feaces and urine sample of patent [6,7,8]. Few features are as follows:

- India like many countries has also has instituted lockdowns and social distancing to control COVID-19's spread and infections at a manageable level.

- Spread of COVID-19 is rapid.

- Most individuals with COVID-19 show no or mild symptoms.

- Nation-wide lockdown may avert sudden and large increase in the number of infections in the short-term.

- Social distancing and isolation of infected individuals over several months can reduce peak infections.

- Frequent hand washing, reduced mass gatherings, contact tracing and quarantines can slow transmission and reduce overall infections.

- Rapid testing is expected to see additional cases in near future due to increased testing of the population.

\section{Management and Vaccination}

Recommended isolation measures are normal measures for this type of transmission i.e. distance between patients, use of individual rooms, use of waterproof gowns, gloves, goggles and surgical masks or FFP2 masks for health personnel except in situations of special risk ${ }^{[9,10,11,12]}$. There is no specific treatment although different experimental treatments with antiviral drugs and interferon are being used. In Spain, prevention, surveillance and control systems for this new disease are adapted to the guidelines and protocols of ECDC and WHO. In the absence of special vaccine for this virus as yet, health professionals follow supportive therapy like administration of antipyretic and analgesic, maintenance of hydration, mechanical ventilation as respiratory support and antibiotic in bacterial infections as treatment strategy. Research activities are going on but health professionals are not fully satisfied with any therapy; further clinical research is badly felt $[13,14,15,16,17,18]$.

\section{Use of Hydroxychloroquine}

ICMR has recommended chemoprophylaxis with hydroxychloroquine for asymptomatic healthcare workers treating patients with suspected or confirmed COVID-19, and for asymptomatic household contacts of confirmed cases. Safety of these immunomodulators in people with severe viral illness has not been evaluated. Although few evidences support the antiviral activity of this drug, there is no peer-reviewed support to justify its widespread use for prophylaxis. Shortage of chloroquine, a low-cost anti-malaria drug may lead to preventable morbidity and mortality in India. A blanket recommendation for chemoprophylaxis in the absence of credible evidence is contentious. A clearly informed choice is essential explaining the lack of evidence for its efficacy 
and its potential risks. A drug accepted provisionally in crisis period often becomes commonplace as standard of care for a long time.

\section{Rationale for Lockdown and Quarantine in India}

- Lockdown and quarantine help arresting the rapid spread of the disease that results in large number of infections with many patients in critical care units (CCU).

- Severe cases require ventilators. High transmission rate and likelihood of severe cases may increase the problem. Lockdown and quarantine, if done well, can help minimize the impact of the epidemic.

- Quarantine or isolation helps developing triage protocols to focus on severe cases, reduce mortality, prevent hospitals from becoming further COVID-19 spread, and allow time to build health care capacity.

\section{Policy Implications}

- Risk of resurgence after lockdown or stay-at-home orders are lifted.

- Seasonality to reduce transmissibility of the virus based on the behavior of other corona viruses.

- A long-term reduction in contact rate to reduce the number of high infections and hospitalizations.

- Factors related to climate or the virus to reduce the transmission rate.

- Introduction of measures promoting social distancing over a period of time for reducing the burden on the health care system and risk of mortality for people having elevated risk.

- Temporary lockdown to build capacity of hospitals and health care workers, additional beds and ventilators.

- Rapid deployment of additional health care workers for efficient testing and contact tracing in both urban and rural areas.

- Temporary hospitals to handle the load of admission of infected patients over the next three-month period. Secondary hospital-based transmission fuels the epidemic.

- Immediate and continuing serological surveys to monitor the proportion of the population infected which can inform the government and policy-makers regarding removing quarantines.

- Collection of PPE in advance for healthcare workers to protect themselves.

\section{STRATEGIES FOR COVID-19 CONTROL}

1. In India, complete isolation from the society like developed countries is not possible as most of the people have livelihood problems. Government can concentrate on their money related basic needs to overcome the phenomena and ask certain percentage of salary from both the public and private sectors. Public Distribution System(PDS) can enable people to follow social distancing and self-isolation; otherwise people will pay importance to known hunger than the unknown diseases.

2. Government should provide proper protective gears (like hand wash, sanitizers, masks, etc.) and regularize the price-supply of hand washer and alcohol sanitizers as essential precaution for the COVID-19.

3. Government officials' analysis and transmission of the updated situation with proper datasheets for further proceedings will bring confidence among the people. Affected people, 
once understanding their goodness, will then stay in quarantine without fear for isolation and automatically follow the government guidelines to extinguish COVID-19.

4. Government should make provision for distinctive hospital facilities and amenities with sufficient medical staff and emergency requirements for all.

5. COVID-19 patients should stay in specific wards and must be separated from the general patients in hospital to restrain the hospital spread.

6. Servicing doctors and nurses need to take all the preventive measures and their health status has to be checked frequently. Government can utilize house surgeons, retired doctors and even private doctors in urgency cases.

7. Governments should supervise every situation and take effective decisions on urgent basis.

8. Arrangement for collection of personal protective equipments (PPE) should be made from central storehouse after taking signature of every staff to prevent misuse or individual storage owing to panic.

9. Important information should be communicated to every staff via internet social media. All hospital staffs have to learn reusing PPE after checked by infection control personnel.

10. All entrance doors to the hospital buildings should be kept close to prevent infection. Body temperature of all entrance persons should be checked by forehead thermometer or intra-red thermal camera.

11. National Health Insurance Administration (NHIA) and National Immigration Agency should work together to integrate patients travel history and TOCC history (travel, occupation, contact and cluster) and check the NHI identification card data from NHIA for all visitors entering the hospital. This prevents solitary awaiting line in front of hospital.

12. All patients should be checked several times after their entry in the hospitals for proactive measures of febrile person detection .

13. People entering hospital with fever or respiratory symptoms or coming from epidemic countries or close contact with confirmed COVID-19 infected patients must be referred to emergency department for throat swab immediately.

14. Outpatient clinic with out-door pharmacy outside the building is essential to serve the asymptomatic patients coming from epidemic countries. Doctors there may consult specialist if the concerned doctor cannot handle the disease.

15. All healthcare workers should check their body temperature and report their respiratory symptoms, if any. Hospital staffs coming from epidemic countries or places have to test for COVID-19 and take a chest radiography. They will not be allowed to work until all examinations show negative.

16. A system may be setup to examine patients with suspected COVID-19, rapid progressed pneumonia, persistent fever or respiratory symptoms, poor response to antibiotics, lymphopenia, low procalcitonin, etc. All information is to be transmitted to duty physicians to recheck the patients condition or consult infectious diseases specialists or pulmonologists shortly. Hospitalized patients not certified by infectious diseases specialists or pulmonologists are to be transferred to isolation room for throat swab.

17. Environment should be kept clear and clearance is to be checked by ATP fluorescence assay at random.

18. Maintaining community hospital is crucial in the pandemic crisis to provide the basic medical needs for common people with limited resources.

19. Implementation of mandatory quarantine may lead to shortage of space. A blending of strict self-quarantine in the community and use of new technology like application of big data and 
artificial intelligence(AI) may improve contact tracing and the management of infected patients [19].

20. Epidemiologists can build a model of the outbreak and determine the number of new infections generated by each case; epidemiological data is required besides vigorous control strategies.

21. Indian Council of Medical Research (ICMR) is planning to study the transmitted dissonance of the virus after the lockdown is dissipated to collect the positive samples and understand the evolution of the virus. This step is welcome.

22. Social distancing is the most widely adopted strategy for the alleviation and control of COVID19 in the absence of vaccine[20]. Suppression of social contact in workplaces, schools and other public spheres is the goal of such strategy.

23. Potency of social contacts depends on both the age structure and frequency of contacts. Minimizing morbidity, extreme infection and excess mortality can be a considerable support in public-health planning.

24. Persistent lockdown with intermittent leisure can be taken as an alternative protocol to reduce the infection levels where social contact tracing and quarantining become effective.

\section{SUGGESTIONS}

1. Assuring adequate personal protective equipment to protect healthcare workers.

2. Creating employment guarantee to expand available healthcare workforce and offset unemployment caused by reduced economic activity.

3. Encouraging events and businesses like exhibitions, markets, etc. locally to implement restrictions on crowding at a given time.

4. Balancing for social distancing with reduction of stigma against health workers and sick people.

5. Encouraging public for seeking test and treatment.

6. Allocating shifting duty to employees throughout the week.

7. Providing shelter and care for the sick to reduce the negative impact of restrictions.

8. At present, government spends very low percentage of GDP on health; before this epidemic, the central government would spend around $1 \%$ and state government little over 2\% of GDP on health. They should spend minimum 14-16\% of GDP on health to maintain proper universal healthcare system in India.

9. Major government hospitals are dealing with only corona virus and have stopped treating patients suffering from other diseases like dialysis and cancer. Private hospitals may be issued order to keep beds for COVID-19 patients separately in this crisis period.

10. With rampant testing, places having rampant spread must be locked down for a longer time.

11. Heavy stock of grains lying in FCI that may be rotting can be distributed to the migrant poor at free to lessen the stock. Government can streamline food distribution and stress on mobilizing the entire FCI distribution system up to dealer.

12. To fight the menace of malnutrition, government should not only guarantee that no people die of hunger or starvation but also maintain nutritional standards. People without ration cards should be allowed to access food through the public distribution system.

13. Current welfare mechanisms are inadequate. Welfare schemes have to be more pertinently structured to handle the unexpected situations like lockdown or economic damming.

14. Poor health workers have to be provisioned sufficient equipment to fight corona virus immediately; ventilators need to be bought immediately. 
15. The unhappy part is that people dying and many walking thousands of kilometers due to lockdown because there was no transport. Government should pay attention on first priority basis.

16. There is no comprehensibility on movement of trucks carrying essential goods and other commodities at state borderline due to lockdown. Government should handle this concrete problem.

17. Ongoing containment measures need to be improved in all states by increasing testing. States having inadequate testing, poor early detection efforts and high case fatality will throw substantial hassle in future.

18. Evidences from other countries suggest that asymptomatic COVID-19 is responsible for more transmission than initially apprehended. So, there is a need to trace the contacts of asymptomatic cases and to wear PPE to keep track of the spread of disease.

19. There is lordliness, bigotry and unsystematic protective line of remedy. If these can protect people, pilgrimage places need not closedown. They correctly prevent community transmission.

20. Tablighi organizers are very irresponsible. But to defame the entire Muslim community is counterproductive in their fight against the pandemic. Government and people must promote commiseration, not proscribing people, particularly patients. Rigorous restricting of spurious news is important.

21. Lack of arrangement for food and other facilities for the migrants prior to lockdown shows tremendous restraint. All people have to work jointly with government establishments for the sufferers under the government's directions.

22. Data regarding symptoms and gravity of cases should have correct publicity. This draws attention of the government to revisit the problem, if required.

23. Containment must be sagaciously explained and thus slightly troublesome for those not in immediate proximity; otherwise entire localities may find themselves caught in again as COVID trajectory nears high point.

24. Despite masks becoming compulsory, the most people working around are violating the official directives. Government must check this with others.

25. Low on confidence and bothered by fear psychosis, business and citizens appearing from lockdown will help from clear warning.

26. The Government will acquire more trust of those poor people by acting rapidly and elongating confidence not by mere words, but by actually transferring fund into their bank accounts for three to four months and by issuing ration without much incitation.

\section{Lessons from COVID-19}

1. Development is actually done by chief ministers, state officials, municipalities, panchayats, districts, block development officers(BD0),etc. The central government advises, supports and supervises the tasks and not much else. Credit is to be given also to the moral economy of ordinary people.

2. It is very urgent to stop expecting leadership from China and America. China has made a massive nightmare at its initial response withhold information, victimized its tattletale and continues to obscure.

3. Science knows a lot more than common sense and traditional medicine. Science will help draw us through symptomatic treatment, pursuing, coordinating and communication technologies, social distancing and proper hygiene practices and possibly a vaccine. 
4. Touching is the most common way of infecting COVID-19. Hygiene, distancing and masks only help us control the disease. COVID will be periodic outbreaks and lockdowns like Ebola or SARS.

5. India faces a serious situation. It might have more cases than China. The R0 number which should be less than one is nowhere near. Testing is low in India; figures are underestimated. Lifting of the lockdown may aggravate the problem. Levels of social distancing and hygiene are not good. India could have reach a million cases.

6. Factors like heat, lack of air conditioning, TB vaccinations, natural immunity, etc. are failures. Weak governance, shambolic healthcare, population density, poverty, etc. have more impact. Chinese economy can come back. India is not parallel with China regarding economic and governance strengths. Hence, it requires to keep COVID-19 under control and must accept the challenge ahead. True leadership is to look a obstacle in the eye.

\section{CONCLUSION}

Certainly COVID-19 is a big threat for India. The strategies and policies are helpful to combat the crisis and will result extreme change. All the countries have followed same strategy through their experiences. These distinct courses may help India eliminating COVID-19. However, successful control programs in India result from the experience of managing its explosion overseas. Infection control strategy at various levels of healthcare system differs for different infectious diseases. The policy is to do the best to prevent any possible COVID-19 infection in India.

\section{COMMENT}

Corona virus spreads human to human by direct contact via airborne droplets. Several times of tightening and loosening restrictions have identical impact; but restrictions need to be tightened to avoid high infections and hospitalizations. periodic changes in lockdown policy or garbled policies may result in policy confusion and community weariness for implementation. As per WHO guidelines, it is essential to avoid contact with sick person and public gatherings. There are no anti corona virus vaccine for prevention or treatment; only supporting therapy works. Future research will direct us to counter with corona virus. We must work as a team to give an adequate and proportionate response to this new disease. We have just one world and one health. We must evaluate its evolution in this changing, uncertain situation. WHO indicates, "This is the time for facts, not fear; for science, not rumours; and for solidarity, not stigma". According to the Chinese horoscope, a firm commitment must be established for the radical resolution of problems: a tree cannot be cut down by removing the leaves, the aim is to remove its roots permanently. So be it with the COVID-19.

\section{References}

1. Coronavirus COVID-19 Global Cases by the Center for Systems Science andEngineering(CSSE).AccessedMarch23,2020,https://www.arcgis.com/apps/opsdashboard/index.html\#/bda7 594740fd40299423467b48e9ecf6.

2. WHO. India ramps up efforts to contain the spread of novel coronavirus. AccessedMarch23,2020,https://www.who.int/india/emergencies/novelcoronavirus-2020.

3. R. Lu, X. Zhao, J. Li, P. Niu, B. Yang, H. Wu, et al. Genomic characterisation and epidemiology of 2019 novel coronavirus: implications for virus origins and receptor binding. Lancet, (2020),http://dx.doi.org/10.1016/S0140-6736(20)30251-8.

4. C. Rothe, M. Schunk, P. Sothmann, G. Bretzel, G. Froeschl, C. Wallrauch, et al.Transmission of 2019-nCoV infection from an asymptomatic contact in Germany.N Engl J Med, (2020),http://dx.doi.org/10.1056/NEJMc2001468 
Das, P. K. (2020). A Critical Appraisal Of Covid-19 In India. Archives of Business Research, 8(5). 227-235.

5. K. Kupferschmidt. Study claiming new coronavirus can be transmitted by people without symptoms was flawed. Science, (2020), http://dx.doi.org/10.1126/science.abb1524.

6. Zhu N, Zhang D, Wang W, Li X, Yang B, Song J, et al. A Novel Corona virus from Patients with Pneumonia in China, 2019. 24 January 2020. New England Journal of Medicine.

7. Huang C, Wang Y, Li X, Ren L, Zhao J, Hu Y, et al. Clinical features of patients infected with 2019 novel coronavirus in Wuhan, China. The Lancet. 24 January 2020.

8. Chan JF-W, Yuan S, Kok K-H, To KK-W, Chu H, Yang J, et al. A familial cluster of pneumonia associated with the 2019 novel corona virus indicating person-to-person transmission: a study of a family cluster. The Lancet. 24 January 2020.

9. Ministerio de Sanidad. Neumonía por un nuevo coronavirus (2019-nCov) en China [accessed 4 Feb 2020]. Available from: https://www.mscbs.gob.es/profesionales/saludPublica/ccayes/alertasActual/nCovChina/home.htm.

10. European Centre for Disease Prevention and Control (ECDC). Novel coronavirus [accessed 4 Feb 2020].Available from: https://www.ecdc.europa.eu/en/novel-corona virus-china.

11. Centers for Disease Control and Prevention (CDC). 2019 Novel Coronavirus [accessed 4 Feb 2020]. Available from: https://www.cdc.gov/corona virus/2019-ncov/index.html.

12. OMS. Corona virus[accessed4 Feb 2020].Available from: https://www.who.int/es/healthtopics/coronavirus/coronavirua.

13. Zhao Z, Zhang F, Xu M, Huang K, Zhong W, Cai W, et al. Description and clinical treatment of an early outbreak of severe acute respiratory syndrome (SARS) in Guangzhou, PR China. J Med Microbiol. 2003;52:715-20.

14. Chan JF, Chan KH, Kao RY, To KK, Zheng BJ, Li CP, et al. Broadspectrum antivirals for the emerging Middle East respiratory syndrome coronavirus. J Inf Secur. 2013;67:606-16.

15. Al-Tawfiq JA, Momattin H, Dib J, Memish ZA. Ribavirin and interferon therapy in patients infected with the Middle Eastrespiratory syndrome corona virus: an observational study. Int J Infect Dis. 2014;20:42-6.

16. Al-Qahtani AA, Lyroni K, Aznaourova M, Tseliou M, Al-Anazi MR, Al-Ahdal MN, et al. Middle East respiratory syndrome corona virus spike glycoprotein suppresses macrophage responses via DPP4-mediated induction of IRAK-M and PPAR $\gamma$. Oncotarget. 2017;8(6):9053-66. doi:10.18632/oncotarget.14754.

17. Bin Saeed AA, Abedi GR, Alzahrani AG, Salameh I, AbdirizakF, Alhakeem R, et al. Surveillance and testing for Middle East respiratory syndrome Coronavirus, Saudi Arabia, April 2015-February 2016. Emerg Infect Dis. 2017;23(4):682-5. doi:10.3201/eid2304.161793.

18. Arabi YM, Balkhy HH, Hayden FG, Bouchama A, Luke T, Baillie JK, et al. Middle East respiratory syndrome. N Engl J Med. 2017;376(6):584-94. doi:10.1056/NEJMsr1408795.

19. K. Kupferschmidt. Study claiming new coronavirus can be transmitted by people without symptoms was flawed. Science, (2020),http://dx.doi.org/10.1126/science.abb1524.

20. N. M. Ferguson et al., "Impact of non-pharmaceutical interventions (npis) to reduce covid-19 mortality and healthcare demand", London: Imperial College COVID- 19 Response Team, March 16 (2020), 10.25561/77482.

\section{Acknowledgement}

This paper is devoted to ALMIGHTY GOD who shows HIS blessings in all walks of my life. 